\title{
Hydrogen Production by Microbial Electrolysis Using Nickel and Platinum Deposited EPPG Electrodes
}

\author{
Acelya Secer \\ Department of Chemistry, Cukurova University \\ 01130, Adana, Turkey \\ E-mail: acsecer@cu.edu.tr
}

\begin{abstract}
In this study nickel and platinum deposited edge plane pyrolized graphite (EPPG) electrodes were used in microbial electrolysis for high yield hydrogen production. EPPG electrodes were used as working electrode (anode) and metal deposited EPPG electrodes were used as cathode. $2.0 \mathrm{~g} / \mathrm{L}$ glucose was used in the electrolyte as substrate, and Shewanella oneidensis MR-1was used as exoelectrogenic bacteria. The most effective cathode material was found to be Pt-deposited EPPG. The optimum electrolysis potential for maximum hydrogen production was determined as $0.7 \mathrm{~V}$. Maximum hydrogen yield was found as $2.44 \mathrm{~mol} \mathrm{H}_{2} / \mathrm{mol}$ glucose at optimum conditions with Pt-deposited EPPG cathode.
\end{abstract}

Keywords: hydrogen, microbial electrolysis, EPPG, Shewanella oneidensis MR-1

DOI: $10.7176 / \mathrm{JSTR} / 5-2-17$

\section{Introduction}

Hydrogen is the most likely powerful candidate to be used in many areas instead of fossil fuels. If it can be obtained from renewable sources, it will not only reduce the need for fossil fuel consumption and meet the energy need in a sustainable way but also will reduce the emission of greenhouse gases and other pollutant gases into the atmosphere. Researches have shown that bacteria can be used in production of hydrogen gas by an electrolysis type microbial fuel cell (MFC) (Liu et al., 2005; Rozendal et al., 2006; Rozendal and Buisman, 2005). The microbial fuel cell (MFC) is a bio-electrochemical cell in which bacteria consume an energy source (glucose, acetic acid etc.) and directly converts the existing chemical energy of a substrate into electrical energy by oxidative transformations at the anode, while chemical and microbial reduction processes are carried out in the cathode section. Bacteria live on the anode and convert the substrate into carbon dioxide, protons and electrons. These bacteria, which typically have electrochemically active redox proteins such as cytochromes on their outer membrane that can transfer electrons directly to the anode, are called as exoelectrogenic (Logan 2009). The electrons then flow through an electric circuit to the cathode. The potential difference between the anode and the cathode together with the electron flow results in the formation of electrical power. A microbial electrolysis cell (MEC) is a MFC related technology in which an additional voltage is supplied to the cell and the transferred electrons are used to reduce protons at the cathode to produce hydrogen. In this method, it is possible to produce hydrogen with relatively smaller potential application than standard electrolysis processes since some of the energy needed for this reduction is derived from the bacterial activity. In some studies, yields of up to $100 \%$ have been obtained in the conversion of hydrogen in the organic substrate to hydrogen gas, and the electrical energy used per unit hydrogen produced in microbial electrolysis is much less than that used in conventional electrolysis of water (Logan et al., 2008). Studies on electrode materials, cathode materials and catalysts, substrates, types of exoelectrogenic bacteria, the new applications and the current challenges and the future prospects are included in the literature (Kadier et al., 2016). Edge plane and basal plane pyrolytic graphite electrodes are fabricated from highly ordered pyrolytic graphite (HOPG). The basal plane surface of an HOPG electrode consists of layers of graphite which lie parallel to the surface and with an interlayer spacing of $3.35 \AA$. Surface defects occur in the

140 | P a g e

www.iiste.org 
form of steps exposing the edges of the graphite layers. Due to the nature of the chemical bonding in graphite, the two planes, edge and basal, exhibit completely different electrochemical properties. For electrochemistry the edge plane pyrolytic graphite (EPPG) exhibits considerably faster electrode kinetics in comparison with the basal plane pyrolytic graphite (BPPG) as edge plane sites/defects on the electrode surface result in faster electron transfer (Banks et al., 2006). In this study, we used EPPG electrodes as anode and metal deposited EPPG electrodes as cathode respectively in a MEC and performed the microbial electrolysis experiments of model compound glucose with Shewanella Oneidensis MR-1 as exoelectrogenic bacteria for high yield hydrogen production. The lower the hydrogen gas production over potentials on the cathode, the lower the potential to be supplied to the MEC system and the higher the energy efficiency of the system. Platinum and Nickel metals were deposited on EPPG surfaces to reduce the over potentials during hydrogen formation on the cathode surface.

\section{Materials and Method}

2.1 Materials

2.1.1 Microorganisms

Shewanella oneidensis MR-1, obtained from commercial and academic sources from USA, was used as exoelectrogenic bacteria.

\subsubsection{Electrodes}

Edge plane pyrolysed graphite (EPPG, Momentive PG plate UEK, USA) was used as anode; EPPG, nickel deposited EPPG and platinum deposited EPPG were used as cathode in the microbial electrolysis cell.

\subsection{Method}

2.2.1 Design of the Microbial Electrolysis Cell

A One-chambered and non-membrane cell was used in the microbial electrolysis experiments. A water circulator (Huber Compatible Control CC1) was used for maintaining the temperature constant. There are 6 inputs and outputs ( $\mathrm{pH}$ probe input, reference electrode input, 2 electrode inputs, gas outlet, and sampling input) in the cover part of the electrolysis cell. The cell and the lid were sealed by clamping the steel with a clamp after a silicone O-ring was placed in order to ensure sealing between them. All of the inlets in the cover section are tightly closed with a suitable septum lid. One end of the hose attached to the gas outlet is closed with a septum lid and the other end is placed in a burette filled with water. In this way, the gas released during the electrolysis is replaced with water and collected in the burette, and the volume of produced gas is measured.

\subsubsection{Preparation of Electrodes}

In this study, EPPG electrodes which will be used as anode and / or cathode were prepared by cutting them from the edge plane. These parts were cut to a size of $39 \times 5 \times 5 \mathrm{~mm}$ and fixed to a glass bar after bonding to a copper wire of $0.2 \mathrm{~mm}$ thickness to provide electron transfer in the electrical circuit. The basal plane, which is not in contact with the solution, is covered with epoxy.

The nickel and platinum deposited EPPG electrodes were prepared by electrochemical deposition. During the electrolytic Ni deposition, a solution consisted of $30 \% \mathrm{NiSO}_{4} .7 \mathrm{H}_{2} \mathrm{O}, 7 \% \mathrm{NiCl}_{2} .6 \mathrm{H}_{2} \mathrm{O}, 1.25 \%$ $\mathrm{H}_{3} \mathrm{BO}_{3}$ was used as electrolyte. The working electrode of the EPPG electrode to be Ni deposited, was electrolyzed for 5 hours at $-20 \mathrm{~mA}$ current at $-20 \mathrm{~mA}$ in an electrochemical cell in which Pt electrode was used as the counter electrode and the $\mathrm{Ag} / \mathrm{AgCl}$ (sat) was used as reference electrode (Solmaz et al., 2012). The Pt deposited EPPG electrodes were cut to size 39 × 5 x 5 and covered with epoxy to prevent the reduction of the basal surfaces. During Pt deposition, an electrolyte solution consisted of $0.8 \%$ (w/ w) $\mathrm{KCl}, 0.6 \%(\mathrm{w} / \mathrm{w}) \mathrm{H}_{3} \mathrm{BO}_{3}, 0.3 \%$ (w/w) $\mathrm{NaC}_{6} \mathrm{H}_{5} \mathrm{O}_{7}$ and $0.00 \% \mathrm{H}_{2} \mathrm{PtCl}_{6}$. At the end of the process, the amount of $\mathrm{Ni}$ and $\mathrm{Pt}$ reduced on the electrodes were calculated theoretically by using the Faraday's law.

\subsubsection{Preparation of Standard Electrolysis Solutions}

The electrolysis solution was consisted of; $\mathrm{MgSO}_{4} .7 \mathrm{H}_{2} \mathrm{O}(0.125 \mathrm{~g} / \mathrm{L}), \mathrm{K}_{2} \mathrm{HPO}_{4}(0.5 \mathrm{~g} / \mathrm{L}), \mathrm{KH}_{2} \mathrm{PO}_{4}(0.5$ $\mathrm{g} / \mathrm{L}), \mathrm{NaCl}(1.0 \mathrm{~g} / \mathrm{L})$, pepton $(5.0 \mathrm{~g} / \mathrm{L})$. , L-cysteine $\mathrm{HCl} . \mathrm{H}_{2} \mathrm{O}(0.05 \mathrm{~g} / \mathrm{L})$ and yeast extract $(0.3 \mathrm{~g} /$ L) forms. When necessary, the $\mathrm{pH}$ of this solution was adjusted to 7.0 with $1.0 \mathrm{M} \mathrm{NaOH}$ solution.

141 | P a g e

www.iiste.org 


\subsubsection{Electrochemical Characterization of Electrodes}

In order to characterize the deposited Pt and Ni particles on EPPG, cyclic voltammetry technique was used. For each electrode material, the electrode to be characterized was used as the working electrode, the Pt plate electrode was used as counter electrode and, $\mathrm{Ag} / \mathrm{AgCl}$ (sat.. $\mathrm{KCl}$ ) was used as reference electrode. The electrolyte solution was $1.0 \mathrm{M} \mathrm{H}_{2} \mathrm{SO}_{4}$. The voltamograms were taken in the range of $-0.8 \mathrm{~V}$ $/ 1.4 \mathrm{~V}$ potentials.

\subsubsection{Microbial Electrolysis Experiments}

$500.0 \mathrm{~mL}$ of electrolysis solutions were prepared with glucose $(2.0 \mathrm{~g} / \mathrm{L})$ using Shewanella oneidensis $M R-1$ as exoelectrogenic bacteria. The bacterial culture was precipitated by centrifugation at $4000 \mathrm{rpm}$ for 15 minute and then transferred to the electrolyte. Experiments were performed at constant potentials of $0.5 \mathrm{~V} ; 0.7 \mathrm{~V}$ and $1.0 \mathrm{~V}$ using a potentiostat (Iviumstat Soft, Model 362) as a power source. Electrolysis processes were carried out for 24 hours. Solutions were stirred with a magnetic stirrer (IKA) at a rate of $150 \mathrm{rpm}$ and at a temperature of $30^{\circ} \mathrm{C}$ during the process. Before starting experiments, nitrogen gas was passed through the solutions. The total volumes of gas produced after experiments were determined volumetrically with a gas burette and the compositions of were determined by a Varian GC-450 model gas chromatograph equipped with double channel and double TCD detector. Molsieve 5A (1m x1 / 8100 Ultimetal) column was used for hydrogen and Shincarbon (100/120 mesh $2 \mathrm{~m} \mathrm{x} \mathrm{1/16} \mathrm{A} \mathrm{x} \mathrm{1mm)} \mathrm{column}$ was used for gases other than hydrogen. Liquid samples which were taken for liquid analysis at the beginning and end of the experiments were first centrifuged at $5000 \mathrm{rpm}$ for $45 \mathrm{~min}$ and then filtered through a $0.45 \mu \mathrm{m}$ syringe type filter and analyzed by Shimadzu 10VP Series HPLC. This device includes refractive index detector (Shimadzu RID-10A), diode array detector (DAD, Shimadzu SPD-M10A VP), oven (Shimadzu CTO-10AS VP), auto sampler (Shimadzu SIL-10AF Automatic Sample Injector), manual injector, equipped with fraction collector (Shimadzu FRC-10A), 2 pumps (Shimadzu LC-6AD), air bubble remover (Shimadzu DGU-14A) and system control provider (Shimadzu SCL-10A VP).

\section{Results}

In the microbial electrolysis mechanism, exoelectrogenic microorganisms interact with the anode material to provide electron transfer after consuming the carbon source in the solution. For this reason, the anode material which will be used in the system must have an appropriate surface chemistry that can interact with bacteria, as well as high conductivity. For this reason, EPPG was chosen as the electrode material due to its highly reactive edge plane which considered being effective compared to the carbon derivative materials used in other studies. While the electron transfer is carried out at the anode, $\mathrm{H}^{+} / \mathrm{H}_{2}$ reduction is carried out at the cathode. The potentials to which this transformation takes place are largely dependent on the over potentials of the electrodes. Therefore, the over potential values of the cathode material will have a great effect on hydrogen production. For this reason, it is aimed to reduce the over voltages by depositing $\mathrm{Ni}$ and Pt on EPPG electrodes which will be used as cathode and therefore, it is aimed to obtain high amount of $\mathrm{H}_{2}$ gas at lower potentials.

The amounts of deposited metals on the electrodes were calculated as $1.7 \mathrm{mg} / \mathrm{cm}^{2} \mathrm{Pt}$ and $6.2 \mathrm{mg} / \mathrm{cm}^{2}$ Ni Faraday's law. The deposited Ni and Pt particles on EPPG surfaces were characterized by cyclic voltammetry and results were compared to the standard EPPG electrodes (Figure 1). The voltammogram of Pt deposited EPPG was different than that of the standard EPPG electrode and the indicating the changes on the surface after Pt deposition. The peaks around $0.4 \mathrm{~V}$ and about $-0.3 \mathrm{~V}$ in the Pt-deposited EPPG electrode were similar to those in the standard Pt electrode which proved the presence of $\mathrm{Pt}$ particles on the EPPG surface. 


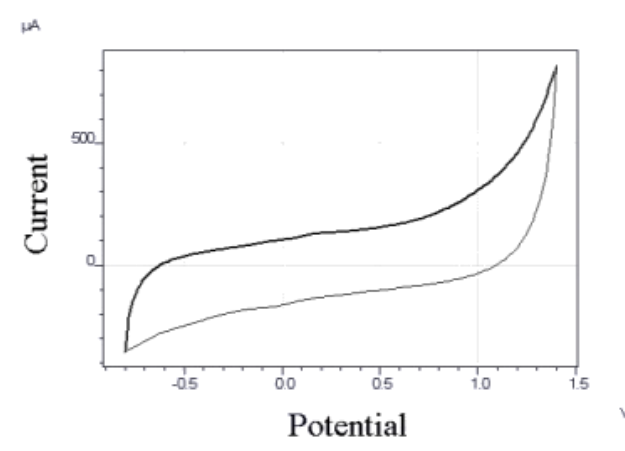

(a)

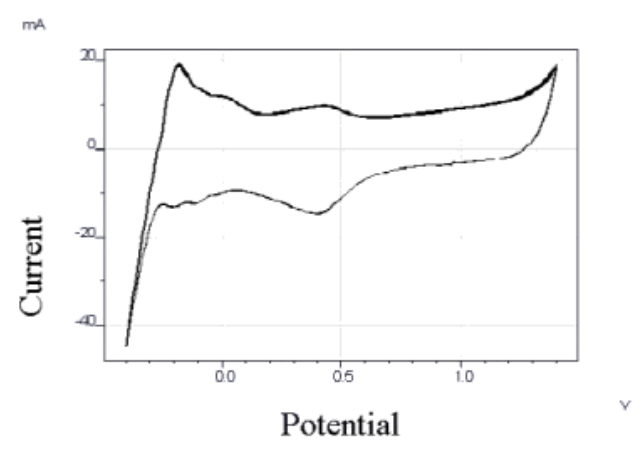

(b)

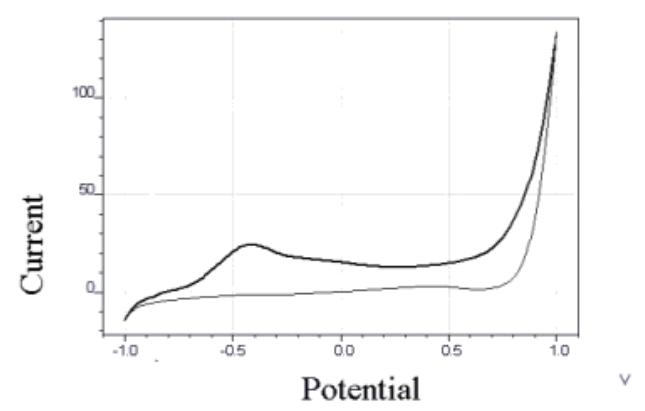

(c)

Figure 1.Cyclic voltammograms of; (a) standard EPPG electrode; (b) Pt-deposited EPPG electrode; (c) Ni-deposited EPPG electrode

In the second part of the study, the microbial electrolysis experiments were performed at three different potentials of $0.5 \mathrm{~V}, 0.7 \mathrm{~V}$ and $1.0 \mathrm{~V}$ using the Pt and $\mathrm{Ni}$ deposited EPPG electrodes as cathode, and standard EPPG electrodes as anode. The product gases were mainly consisted of hydrogen and carbon dioxide but the major product was hydrogen in all experiments. Total gas volumes and the percentage ratios of hydrogen and carbon dioxide in the produced gases were given in Table 1. The total gas volume was $297.5 \mathrm{~mL}$ with a ratio of $86.5 \% \mathrm{H}_{2}$ for Ni-deposited EPPG electrode. In this case, the optimum potential for microbial electrolysis tests where Ni-deposited EPPG electrode was used as cathode was 0.7 and the maximum amount of hydrogen was calculated as $10.6 \pm 1.81 \mathrm{mmol}$. According to the results of the table, for the Pt-deposited EPPG electrode was used as a cathode, the highest gas volume was obtained at $0.7 \mathrm{~V}$ potential. In addition, the amount of $\mathrm{H}_{2}$ gas in the gas composition obtained in this application potential was also considerably higher than the amounts obtained in other application potentials $(88.1 \%)$. Hence, at the optimum application potential of $0.7 \mathrm{~V}$ and the maximum hydrogen gas obtained at the end of 24 hours was determined as $13.4 \pm 1.67 \mathrm{mmol}$ for Pt-deposited EPPG electrode. The total gas and hydrogen production efficiencies were higher than standard EPPG in both experiments in which Ni-deposited and Pt-deposited EPPG were used as cathode. This result was attributed to the reduction of over potentials of the EPPG electrodes by metal deposition. Liquid samples, which were collected after electrolysis experiments, were also analysed by HPLC and the content of post-electrolysis solution were determined. The results of the liquid sample analyses were given in Table 2. 
Table 1. Total gas volumes and gas compositions obtained from the microbial electrolysis experiments at different potentials using EPPG, Ni-deposited EPPG and Pt-deposited EPPG electrodes as cathode.

\begin{tabular}{|c|c|c|c|c|c|c|c|c|c|}
\hline \multirow{2}{*}{ 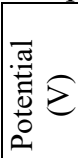 } & \multicolumn{3}{|c|}{$\begin{array}{c}\begin{array}{c}\text { Total Gas volume } \\
(\mathrm{mL})\end{array} \\
\end{array}$} & \multicolumn{3}{|c|}{$\mathrm{H}_{2}(\%)$} & \multicolumn{3}{|c|}{$\mathrm{CO}_{2}(\%)$} \\
\hline & EPPG & $\mathrm{Ni}^{-E P P G}{ }^{\mathrm{a}}$ & $\mathrm{Pt}^{\mathrm{EPPG}}{ }^{\mathrm{b}}$ & EPPG & Ni-EPPG & $\begin{array}{l}\text { Pt- } \\
\text { EPPG }\end{array}$ & EPPG & $\begin{array}{l}\mathrm{Ni}- \\
\mathrm{EPPG}\end{array}$ & $\begin{array}{l}\text { Pt- } \\
\text { EPPG }\end{array}$ \\
\hline 0.5 & $149.5 \pm 34.7$ & $7156.0 \pm 8.4$ & $254.0 \pm 12.7$ & $784.0 \pm 0.3$ & $85.0 \pm 0.8$ & $87.3 \pm 0.9$ & $16.0 \pm 0$ & $115.0 \pm .01$ & $112.7 \pm 0.1$ \\
\hline 0.7 & $245.0 \pm 35.4$ & $297.5 \pm 48.8$ & $8369.5 \pm 40.3$ & $89.2 \pm 0.6$ & $86.6 \pm 0.6$ & $88.1 \pm 0.7$ & $10.8 \pm 0$ & $113.4 \pm 0.1$ & $11.9 \pm 0.1$ \\
\hline 1.0 & $135.0 \pm 4.2$ & $159.5 \pm 3.5$ & $241.0 \pm 5.6$ & $88.4 \pm 0.2$ & $86.2 \pm .0 .4$ & $85.5 \pm 0.5$ & $11.6 \pm 0.1$ & $13.8 \pm 0.1$ & $14.5 \pm 0.1$ \\
\hline
\end{tabular}

${ }^{\mathrm{a}} \mathrm{Ni}$-deposited EPPG electrode; ${ }^{\mathrm{b}} \mathrm{Pt}$-deposited EPPG electrode

Table 2. The products observed with HPLC analyses of the liquids which were sampled after electrolysis experiments.

\begin{tabular}{|c|c|c|c|c|c|c|c|c|c|}
\hline Cathode & \multicolumn{3}{|c|}{ EPPG } & \multicolumn{3}{|c|}{ Ni-EPPG } & \multicolumn{3}{|c|}{ Pt-EPPG } \\
\hline $\begin{array}{c}\begin{array}{c}\text { Potential } \\
(\mathrm{V})\end{array} \\
\begin{array}{l}\text { Product } \\
(\mathrm{mmol})\end{array}\end{array}$ & 0.5 & 0.7 & 1.0 & 0.5 & 0.7 & 1.0 & 0.5 & 0.7 & 1.0 \\
\hline $\begin{array}{l}\text { Lactic } \\
\text { acid }\end{array}$ & $0.12 \pm 0.02$ & $0.72 \pm 0.07$ & $1.32 \pm 0.33$ & $1.78 \pm 0.014$ & $0.39 \pm 0.07$ & $0.42 \pm 0.04$ & $0.43 \pm 0.11$ & - & - \\
\hline $\begin{array}{l}\text { Formic } \\
\text { acid }\end{array}$ & $4.79 \pm 0.90$ & $4.13 \pm 1.35$ & $4.02 \pm 1.87$ & $0.19 \pm 0.09$ & $0.72 \pm 0.07$ & $0.18 \pm 0.06$ & $1.11 \pm 0.06$ & $0.73 \pm 0.02$ & $2.42 \pm 0.01$ \\
\hline $\begin{array}{l}\text { Acetic } \\
\text { acid }\end{array}$ & $6.90 \pm 3.40$ & $9.41 \pm 4.67$ & $6.22 \pm 0.74$ & $9.98 \pm 0.04$ & $6.58 \pm 0.03$ & $5.05 \pm 0.05$ & $4.69 \pm 0.44$ & $5.65 \pm 0.07$ & $3.08 \pm 0.01$ \\
\hline $\begin{array}{l}\text { Propionic } \\
\text { acid }\end{array}$ & $0.91 \pm 0.20$ & $1.37 \pm 0.40$ & $1.46 \pm 0.07$ & $1.67 \pm 0.16$ & $0.72 \pm 0.28$ & $0.59 \pm 0.07$ & $0.39 \pm 0.07$ & $0.28 \pm 0.01$ & $0.21 \pm 0.01$ \\
\hline $\begin{array}{c}\text { Butyric } \\
\text { acid }\end{array}$ & $1.42 \pm 1.29$ & $1.87 \pm 0.90$ & $2.13 \pm 0.05$ & $1.56 \pm 0.49$ & $3.45 \pm 0.50$ & $3.08 \pm 0.01$ & $3.38 \pm 0.09$ & $4.22 \pm 0.04$ & $3.42 \pm 0.01$ \\
\hline
\end{tabular}

\section{Conclusions}

According to the results, the optimum application potential for the maximum amount of hydrogen gas for all electrode combinations was determined as $0.7 \mathrm{~V}$ which is relatively lower than the standard electrolysis potential of water $(1.23 \mathrm{~V})$ for hydrogen production. The amount of hydrogen with $\mathrm{Ni}$ deposited EPPG $(10.6 \pm 1.8 \mathrm{mmol})$ and Pt-deposited EPPG electrodes $(13.4 \pm 1.6 \mathrm{mmol})$ were higher than that of the standard EPPG electrode $(7.8 \pm 1.2 \mathrm{mmol})$. In addition, the amount of hydrogen gas produced by the Pt-deposited EPPG was also significantly higher than that obtained with Ni-deposited EPPG. As a result, Pt-deposited EPPG electrode was found as the most effective cathode material at the $0.7 \mathrm{~V}$ application potential among standard EPPG and Ni-deposited EPPG. The hydrogen yield (mol $\mathrm{H}_{2}$ / mol glycose) obtained in a 24-hour microbial electrolysis application under these conditions was calculated to be $2.44 \mathrm{~mol} \mathrm{H}_{2} / \mathrm{mol}$ glucose. Deposition of $\mathrm{Ni}$ and Pt metals resulted in an increase in both total gas and hydrogen gas formations.

\section{References}

Call, D., Logan, B.E. (2008). Hydrogen Production in a Single Chamber Microbial Electrolysis Cell (Mec) Lacking A Membrane. Environmental Science \& Technology, 42, 3401-3406 
Cheng, S., Logan, B.E. (2007). Ammonia Treatment of Carbon Cloth Anodes to Enhance Power Generation Of Microbial Fuel Cells. Electrochemistry Communications, 9, 492-496.

Cheng, S., Logan, B.E. (2007). Sustainable and Efficient Bio hydrogen Production via Electrohydogenesis. Proceedings of the Nation Academy Of Sciences, 104, 18871-18873.

Hallenbeck, P.C., Benemann, J.R. (2002). Biological Hydrogen Production; Fundamentals and Limiting Processes. International Journal of Hydrogen Energy, 27, 1185-1193.

Hawkes, F.R., Hussy, I., Dinsdale, R., Hawkes, D.L., Hussy, I. (2002). Sustainable Fermentative Hydrogen Production: Challenges for Process Optimization. International Journal of Hydrogen Energy, 27, 1339-1347.

Kadier. A., Simayi, Y., Abdeshahian, P., Azman, F.N., Chandrasekhar, K., Khalil, M.S. (2016). A Comprehensive Review of Microbial Electrolysis Cells (MEC) Reactor Designs and Configurations for Sustainable Hydrogen Gas Production. Alexandria Engineering Journal, 55(1), 427-443.

Kim, H.J., Park, H.S., Hyun, M.S., Chang, I.S., Kim, M., Kim, B.H. (2002). A Mediator-Less Microbial Fuel Cell Using A Metal Reducing Bacterium, Shewanella Putrefaciens. Enzyme and Microbial Technology, 30, 145-152.

Liu, H., Grot, S., Logan, B.E. (2005). Electrochemically Assisted Microbial Production of Hydrogen from Acetate. Environmental Science \& Technology, 39, 4317-4320.

Logan, B.E., Call, D., Cheng, S., Hamelers, H.V.M., Sleutels, T.H.J.A., Jeremiasse, A.W., And Rozedal, R.A. (2008). Microbial Electrolysis Cells for High Yield Hydrogen Gas Production from Organic Matter. Environmental Science \& Technology, 42 (23), 8630-8640.

Logan, B.E., Hamelers, B., Rozendal, R., Scröder, U., Keller, J., Freguis, S., Aelterman, P., Verstraete, W., Rabaey, K. (2006). Microbial Fuel Cells: Methodology and Technology. Environmental Science \& Technology, 40, 5181-5192.

Meshulam-Simon, G., Behrens, S., Choo, A.D., And Spormann, A.M. (2007). Hydrogen Metabolism in Shewanella Oneidensis Mr-1. Applied An Environmental Microbiology, 73, 1153-1165.

Rozendal, R.A., Hamelers, H.V.M., Buisman, C.J.N. (2006). Effects of Membrane Cation Transport on Ph And Microbial Fuel Cell Performance. Environmental Science and Technology, 40, 17, 5206-5211.

Rozendal, R.A., Buisman, C.J.N. (2005). Process of Producing Hydrogen. Patent Wo2005005981

Solmaz, R., Gündoğdu, A., Döner, A., Kardaş, G. (2012). The Ni-Deposited Carbon Felt As Substrate for Preparation of Pt-Modified Electrocatalysts: Application for Alkaline Water Electrolysis. International Journal of Hydrogen Energy, 37 (11), 8905-9450. 